\title{
1 Rate-Related Kinematic Changes in Younger and Older Adults
}

2 van Brenk $\mathbf{F}_{{ }^{a}}^{\mathrm{a}-\mathrm{c}} \cdot$ Terband $\mathrm{H}_{0^{\mathrm{a}}, \mathrm{c}, \mathrm{d}} \cdot \operatorname{van}$

3 Lieshout P. ${ }^{\mathrm{e}} \cdot$ Lowit A. $^{\mathrm{b}} \cdot$ Maassen B. $^{\mathrm{c}, \mathrm{d}}$

$4 \quad$ a Utrecht Institute of Linguistics - OTS, Utrecht University, Utrecht, The Netherlands; ${ }^{\mathrm{b}}$ Speech and

5 Language Therapy Unit, University of Strathclyde, Glasgow, UK; ${ }^{\mathrm{c}}$ Medical Psychology/Pediatric

6 Neurology Centre/ENT, Radboud University Nijmegen Medical Centre, Nijmegen, and ${ }^{\mathrm{d}}$ Center for

7 Language and Cognition Groningen, University of Groningen, Groningen, The

8 Netherlands; ${ }^{\text {}}$ Department of Speech-Language Pathology, Oral Dynamics Lab, and Department of

9 Psychology, Institute of Biomaterials and Biomedical Engineering, and Graduate Department of

10 Rehabilitation Science, University of Toronto, and Toronto Rehabilitation Institute, Toronto, Ont.,

11 Canada

13 Introduction

14 It is well documented that speech production changes across the lifespan. Research 15 has reported modifications to jaw and tongue muscle anatomy [1] as well as changes

16 in articulator function, such as a decrease in muscle activity [2] or strength and

17 rhythm of tongue movements with increasing age $[3,4]$. Regarding speech output,

18 many studies have found a decrease in speech rate and speech accuracy in older

19 compared to younger speakers [5,6], although not all research confirms these findings 20 [7].

21 A number of studies set out to capture these changes in rate through the

22 detailed investigation of articulator movement. For example, it has been shown that

23 an increase in speech rate is related to either a decrease in movement amplitude or an

24 increase in movement velocity of articulatory opening and closing movements [8]. A

25 reduction in speech rate on the other hand, is associated with an increase in movement 
1 duration [9,10]. Goozee, Stephenson, Murdoch, Darnell, and Lapointe [11] assessed

2 age-related differences in speech kinematics and found that with increasing syllable

3 repetition rates, participants from all age groups reduced tongue movement distances

4 during consonant production, but the effect was significantly smaller in older adults

5 compared to younger adults. In addition, the older adults showed a trend towards a

6 relatively lower velocity and lower acceleration with increasing syllable repetition

7 rates. The authors hypothesized that the older adults might have used a compensatory

8 strategy in the face of reduced neuromuscular control in order to maintain articulatory

9 stability or speech accuracy. Alternatively, a possible age-related decrease in

10 proprioception of the tongue could lead to a decreased ability to judge tongue

11 distances, thus making it difficult for older adults to actively reduce distances while

12 increasing rate [11]. The experimental setup did not allow for definite conclusions,

13 since in the fast condition syllable repetition rates were self-chosen and realized

14 consistently slower in the group of older compared to younger adults. The question

15 thus remains whether the observed differences resulted from a limitation in speech

16 motor control (i.e., older individuals could not go any faster) or from differences in

17 effort (i.e., older individuals preferred not to go any faster). In fact, other studies

18 suggest that older adults prefer to monitor their speech production more carefully than

19 younger adults with the intent of maximizing speech intelligibility, naturalness and

20 accuracy, at the cost of rate [12].

21 The aim of the current study was to investigate the effects of aging on the

22 kinematic characteristics and stability of speech movements, addressing some of the

23 central, theoretically distinctive questions that arose from the previous studies by

24 using both a self- and a metronome-paced syllable repetition task, allowing to study

25 specific aspects of speech motor control across ages and clinical populations. The 
1 metronome-paced task constitutes an important addition to previous studies as this

2 provides a way to control for possible age-related preferential differences in speaking

3 rates.

With a possible age-related reduced neuromuscular control or decreased

5 articulator proprioception in mind, one could assume that in the self-paced task older

6 adults will either match the syllable repetition rates of younger speakers, but with

7 decreased stability, or choose to speak slower in order to maintain movement stability

8 and/or accuracy. Based on the above-mentioned age-related declines in oral sensation,

9 we would expect older adults to show a decline in the stability of speech motor

10 movements compared to the younger adults if they are forced to speed up their

11 syllable repetition rates in the metronome-paced task. Alternatively, as some

12 kinematic studies have shown that healthy aging individuals are able to compensate

13 for age-related anatomical and functional changes in speech tasks [7], we would

14 expect to find similar stability compared to younger adults, but with different

15 underlying kinematics.

\section{$17 \quad$ Method}

\section{Participants}

19 Eight young adults, two males and six females aged $21-27$ (mean $=23.7$ years, $S D=$ 202.3 years) and eight older speakers, four males and four females, aged 66-84 (mean = 2174.7 years, $\mathrm{SD}=6.0$ years) participated in the study. The participants were native 22 speakers of Dutch without a current history of speech problems. In the group of older 23 adults, four subjects had full or partial dental plates or prostheses. All had been 24 wearing them for more than one year, and wore them during the study. Two subjects 
1 in the group of older adults had hearing aids, but reportedly used them only rarely.

2 Neither used their hearing aids during the experiments. Based on participants' self

3 reports and informal assessment during conversation prior to the recordings, the

4 hearing and speech of all participants was judged to be within normal ranges for

5 taking part in the study.

\section{Instrumentation and procedures}

8 Data collection was carried out in accordance with previous studies [13]. An AG100

9 Carstens Electro-Magnetic Midsagittal Articulograph (EMMA; Carstens

10 Medizinelektronic, GmbH, Germany) was used to collect articulatory movement data

11 and time-aligned audio recordings. The system is equipped with a helmet containing

12 three transmitting coils in midsagittal direction. Transducer coils were attached to the

13 midline positions of the vermillion border of upper lip and lower lip as well as the

14 nose bridge and to the lower and upper incisor gums. The coils attached on the upper

15 incisor gums and the nose bridge were used as reference points for positional data.

16 Three were placed onto the tongue (tongue blade, tongue body, and tongue dorsum).

17 After attachment of the transducer coils, participants engaged in an everyday

18 conversation of around 5 minutes to allow them to get used to speaking with coils on

19 their articulators. Once the speech of participants was judged to be unaffected, formal 20 assessment started.

\section{Tasks}

23 The participants were instructed to repeat a set of monosyllabic utterances in trials of

2412 seconds. The syllables were made up in a CV format: /pa/,/sa/, and /ta/. The 
1 syllables were recorded in two pacing conditions: self-paced and after being trained

2 by a metronome. In the self-paced condition, participants were instructed to repeat the

3 items at their chosen habitual, slow and fast rate. In the metronome condition, a

4 digital metronome (Adobe Audition v1.5) was used to train participants to maintain a

5 specified syllable repetition rate. Metronome speed was set at 2, 2.5, 3, 3.5, and 4

6 beats per second (bps). Prior to recording, the metronome was started to allow

7 participants to mentally tune in to the beat rate. Participants were instructed to

8 fluently and on a single breath repeat the syllables as close as possible to the indicated

9 metronome speed, at a rate of one syllable per beat. The subjects gave a hand signal

10 and took a deep breath when they felt to be tuned into the metronome rhythm. Then

11 the metronome was stopped by the experimenter and the recording of syllable

12 repetitions was started. By following this procedure, we were able to cue different

13 syllable repetition rates, while at the same time preventing the impact of enhanced

14 fluency conditions as typically invoked by the presence of an external timing signal

15 similar to methods sometimes used in the treatment of people who stutter [14]. The

16 acoustic recording was played back afterwards, and judged on apparent articulation

17 errors, pauses or rate changes, and if present, the trial was repeated at the end of the

18 recording session.

19 The test items were presented in the order $/ \mathrm{pa} /-/ \mathrm{sa} /-/ \mathrm{ta} /$. To avoid stimulus

20 presentation errors, the self-paced conditions were recorded first, in the order habitual

21 - slow - fast, followed by the metronome paced conditions, also ordered from slow to

22 fast rate. 
1 The acoustic signal was used to calculate syllable repetition rates for each trial. The

2 first and last syllable in each trial was discarded. Within each trial, the fragments used

3 to calculate syllable repetition rates were also used in the kinematic analyses.

The movement patterns were analysed using the principal articulators of each

5 syllable repetition task. For the production of the syllable /pa/, the analysis focused on

6 the bilabial closing movement for $/ \mathrm{p} /$ and subsequent opening movement for the

7 vowel production. The lower lip coil was used to track this activity. For the syllables

$8 / \mathrm{sa} / \mathrm{and} / \mathrm{ta} /$, the alveolar closing and opening movements were analysed by using the

9 tongue tip coil. All movement signals were visually screened for unusual movements

10 and the acoustic data were perceptually screened for interruptions, hesitations or

11 production errors. Trials that contained such errors were excluded, in order to retain

12 only data that were perceptually correct and produced fluently. The kinematic

13 analysis was performed on the first 10 syllable repetitions where available. For one

14 older speaker, five trials had only nine syllable repetitions available, and in one trial

15 there were eight syllable repetitions available. In one trial, only eight syllable

16 repetitions were available from a older speaker.

The Tailor Data Processing Program v1.3 (Carstens Medizinelektronic,

$18 \mathrm{GmbH}$, Germany) and Matlab were used to analyze the data, following procedures

19 described in [15]. For the kinematic measurements of the lower lip, mandible

20 movement contributions were subtracted using a 2D based method that estimates a

21 jaw rotation component, which has been found to be more precise than a simple

22 subtraction procedure [16]. This method was not used for tongue tip movements since

23 it cannot not guarantee uniform results with respect to compensating tongue tip

24 movements for jaw contributions [15]. As tongue tip and jaw are only loosely coupled

25 [17], this would introduce extra, possibly serious, measurement artefacts [18]. An 
1 automated peak-picking algorithm was used to identify and label maximum peak and

2 valley values of the articulatory movement signals using the cyclic spatiotemporal

3 index, or cSTI $[17,19]$. Peak assignment was manually corrected where necessary. For

4 each syllable repetition, the following kinematic parameters were analysed separately

5 for opening and closing movements of the tongue tip (for sa/ and /ta/) and the lower

$6 \operatorname{lip}($ for $/ \mathrm{pa} /$ ): movement duration (in sec), movement amplitude or displacement (in

$7 \mathrm{~mm}$ ), peak velocity (in $\mathrm{mm} / \mathrm{sec}$. Furthermore, the cyclic spatiotemporal index was measured to assess variability of cyclic movement patterns of individual articulators.

Statistical analysis

11 Linear Mixed Model analyses (IBM SPSS v20) were used for statistical analysis,

12 which is general linear model type that does not assume homogeneity of variance,

13 sphericity, or compound symmetry, and allows for missing data [20]. When

14 comparing the means of syllable repetition rates, fixed factors were 'group' (younger

15 adults and older adults), 'rate' (slow, habitual and fast in the self-paced rate condition

16 and 2, 2.5, 3, 3.5 and $4 \mathrm{bps}$ in the metronome condition) and 'task' (/pa/, /sa/ and /ta/).

17 Syllable repetition rates were analysed separately for the self-paced condition and the

18 metronome-paced condition. The kinematic variables were analyzed separately for the

19 two pacing conditions and the three syllable repetition tasks. Fixed factors were

20 'group', 'rate' and 'direction' (opening and closing movements). A Bonferroni

21 correction to adjust for multiple statistical tests was not applied, as this creates an

22 unacceptably high probability of making a Type II error in analyses with small group

23 sizes. Rather, multiple comparisons are accounted for in the interpretation of the

24 results [cf. 21]. Significant main and interaction effects were further explored by

25 means of a pair wise comparison using Fisher's Least Significant Difference Test. 


\section{Results}

3 Prior to comparing syllable repetition rates and kinematic parameters across groups, it

4 was determined whether speakers were sufficiently comparable with each other to

5 allow for further comparisons. Two of the eight older participants had been prescribed

6 hearing aids, although they did not wear them during the experiment. In addition,

7 although the group of older adults was balanced for gender with four females and four

8 males participating, the group of younger adults had an imbalance with six females

9 and two males. Lastly, since four speakers in the group of older adults were wearing

10 full or partial dentals, potential effects of wearing dental plates on articulatory

11 performance were examined. The possible effects of these variables were analyzed by

12 a one-way analysis of variance of mean syllable repetition rates, separately for each

13 syllable type and pooled over pacing method and rate task. There were no significant

14 differences found for these variables, and all participants were included in the

15 subsequent analyses.

\section{$17 \quad$ Syllable repetition rates}

18 The means and standard deviations of the syllable repetition rates are displayed in

19 table 1. A significant effect of group on syllable repetition rate was absent in both

20 pacing conditions. A main effect of rate was present in the metronome condition [F

$21(4,224)=721.7, p<.001]$ and the self-paced condition $[F(2,128)=227.8, p<.001]$;

22 both groups changed syllable repetition rates according to the syllable repetition rate

23 condition. A main effect of task was present in the self-paced condition $[F(2,128)=$

$243.77, \mathrm{p}=.026]$. Post-hoc analysis showed that syllable repetition rates of $/ \mathrm{ta} / \mathrm{were}$ 
1 faster compared to /pa/. Significant interaction effects of group by rate (metronome:

$2[\mathrm{~F}(4,224)=5.84, \mathrm{p}<.001]$, self-paced: $[\mathrm{F}(2,128)=18.80, \mathrm{p}<.001])$ indicated that

3 the group of older adults had faster syllable repetition rates than the young

4 participants at 3, 3.5 and 4 bps in the metronome condition and in the fast rate task of

5 the self-paced condition pooled over the three syllables. A significant interaction

6 effect of group by task in the self-paced condition $[\mathrm{F}(2,128)=7.86, \mathrm{p}=.001]$

7 indicated that the older group was significantly faster during /ta/ pooled over the three

8 rate tasks.

9

10 Table 1. Means and standard deviations (in parentheses) of syllable repetition rates (in syllables per second) for younger and

11 older adults, broken down by task and rate condition.

\begin{tabular}{lcccccc}
\hline & \multicolumn{2}{c}{$/ \mathrm{pa} /$} & \multicolumn{2}{c}{$/ \mathrm{sa} / \mathrm{ta} /$} \\
\hline Rate & Young adults & Older adults & Young adults & Older adults & Young adults & Older adults \\
\hline Slow & $1.23(0.32)$ & $1.21(0.20)$ & $1.63(0.44)$ & $1.45(0.29)$ & $1.82(0.50)$ & $1.29(0.34)$ \\
Habitual & $2.02(0.43)$ & $2.08(0.64)$ & $2.26(0.47)$ & $1.97(0.48)$ & $2.44(0.83)$ & $1.86(0.35)$ \\
Fast & $2.76(0.63)$ & $4.10(1.11)$ & $3.23(0.69)$ & $3.51(0.57)$ & $3.50(1.20)$ & $3.96(0.90)$ \\
\cline { 2 - 6 } $2 \mathrm{bps}$ & $2.00(0.08)$ & $1.91(0.17)$ & $2.03(0.09)$ & $1.94(0.10)$ & $2.05(0.08)$ & $1.99(0.13)$ \\
$2.5 \mathrm{bps}$ & $2.52(0.11)$ & $2.78(0.33)$ & $2.54(0.17)$ & $2.70(0.21)$ & $2.53(0.09)$ & $2.61(0.12)$ \\
$3 \mathrm{bps}$ & $3.06(0.29)$ & $3.37(0.30)$ & $2.98(0.11)$ & $3.19(0.26)$ & $2.98(0.12)$ & $3.20(0.13)$ \\
$3.5 \mathrm{bps}$ & $3.53(0.24)$ & $3.75(0.27)$ & $3.48(0.26)$ & $3.64(0.38)$ & $3.40(0.15)$ & $3.87(0.48)$ \\
$4 \mathrm{bps}$ & $4.18(0.42)$ & $4.37(0.52)$ & $4.01(0.48)$ & $4.13(0.48)$ & $3.99(0.22)$ & $4.55(0.68)$ \\
\hline
\end{tabular}

12

13

14 Table 2. Means and standard deviations (in parentheses) of kinematic parameters for younger and older adults, broken down by

15 task, movement direction and rate condition. $\mathrm{DUR}=$ duration, $\mathrm{AMP}=$ amplitude, $\mathrm{VEL}=$ peak velocity, $\mathrm{CSTI}=$ cyclic

16 spatiotemporal index, $\mathrm{OP}=$ opening, $\mathrm{CL}=$ closing.

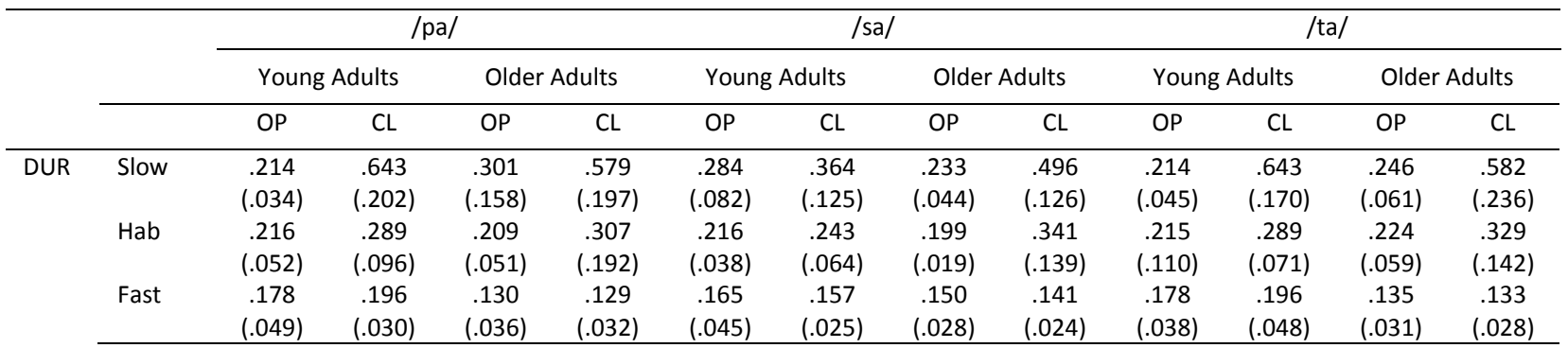




\begin{tabular}{|c|c|c|c|c|c|c|c|c|c|c|c|c|c|}
\hline & \multirow[t]{2}{*}{$2 \mathrm{bps}$} & .216 & .285 & .194 & .312 & .203 & .260 & .200 & .319 & .216 & .285 & .198 & .274 \\
\hline & & $(.032)$ & $(.042)$ & $(.044)$ & $(.097)$ & $(.040)$ & $(.066)$ & $(.022)$ & $(.029)$ & $(.035)$ & $(.040)$ & $(.038)$ & $(.080)$ \\
\hline & \multirow[t]{2}{*}{$2.5 \mathrm{bps}$} & .194 & .201 & .183 & .179 & .200 & .198 & .165 & .207 & .194 & .201 & .174 & .206 \\
\hline & & $(.018)$ & $(.018)$ & $(.031)$ & $(.032)$ & $(.015)$ & $(.016)$ & $(.017)$ & $(.023)$ & $(.025)$ & $(.024)$ & $(.017)$ & $(.015)$ \\
\hline & \multirow[t]{2}{*}{$3 \mathrm{bps}$} & .168 & .164 & .153 & .145 & .166 & .168 & .153 & .162 & .168 & .164 & .155 & .152 \\
\hline & & $(.011)$ & $(.011)$ & $(.013)$ & $(.014)$ & $(.007)$ & $(.008)$ & $(.010)$ & $(.015)$ & $(.017)$ & $(.010)$ & $(.011)$ & $(.009)$ \\
\hline & \multirow[t]{2}{*}{$3.5 \mathrm{bps}$} & .142 & .140 & .134 & .132 & .144 & .144 & .136 & .141 & .142 & .140 & .131 & .129 \\
\hline & & (.009) & $(.008)$ & $(.010)$ & $(.009)$ & $(.011)$ & $(.010)$ & $(.012)$ & $(.016)$ & $(.007)$ & $(.006)$ & $(.015)$ & $(.014)$ \\
\hline & \multirow[t]{2}{*}{$4 \mathrm{bps}$} & .120 & .120 & .116 & .115 & .124 & .125 & .121 & .124 & .120 & .120 & .112 & .112 \\
\hline & & $(.011)$ & $(.011)$ & $(.014)$ & $(.011)$ & $(.012)$ & $(.012)$ & $(.013)$ & $(.013)$ & $(.009)$ & $(.006)$ & $(.015)$ & $(.015)$ \\
\hline \multirow[t]{16}{*}{ AMP } & \multirow[t]{2}{*}{ Slow } & 8.05 & 7.99 & 8.01 & 7.85 & 9.10 & 9.22 & 11.4 & 11.5 & 9.73 & 9.71 & 13.7 & 13.5 \\
\hline & & (3.57) & (3.51) & $(4.25)$ & $(4.13)$ & (4.93) & $(4.81)$ & $(5.60)$ & $(5.67)$ & (5.13) & $(5.11)$ & $(7.60)$ & (7.58) \\
\hline & \multirow[t]{2}{*}{$\mathrm{Hab}$} & 8.51 & 8.51 & 8.00 & 8.02 & 9.71 & 9.96 & 10.8 & 10.9 & 8.97 & 9.36 & 13.5 & 13.4 \\
\hline & & $(4.02)$ & $(4.09)$ & (3.32) & (3.29) & (3.84) & (3.90) & (3.98) & (3.94) & (5.17) & $(5.23)$ & (7.34) & (7.31) \\
\hline & \multirow[t]{2}{*}{ Fast } & 9.02 & 9.02 & 7.98 & 7.96 & 7.83 & 8.09 & 7.24 & 7.48 & 9.00 & 9.09 & 10.7 & 10.7 \\
\hline & & (3.37) & $(3.42)$ & (4.32) & $(4.26)$ & (3.14) & $(3.33)$ & $(2.49)$ & $(2.57)$ & (5.08) & $(5.04)$ & (6.14) & (5.91) \\
\hline & \multirow[t]{2}{*}{$2 \mathrm{bps}$} & 8.12 & 8.16 & 9.56 & 9.54 & 8.60 & 8.73 & 9.25 & 9.30 & 10.1 & 10.0 & 12.8 & 12.9 \\
\hline & & (3.71) & (3.79) & (5.39) & (5.59) & $(3.82)$ & $(3.94)$ & $(3.02)$ & $(3.05)$ & $(5.21)$ & $(5.16)$ & (7.66) & (7.61) \\
\hline & \multirow[t]{2}{*}{$2.5 \mathrm{bps}$} & 8.35 & 8.46 & 8.40 & 8.25 & 7.45 & 7.70 & 8.79 & 9.04 & 8.96 & 9.07 & 10.7 & 10.8 \\
\hline & & (3.77) & (3.77) & (3.99) & (3.85) & $(2.70)$ & $(2.83)$ & (3.29) & (3.27) & (4.15) & $(4.26)$ & $(4.80)$ & $(4.79)$ \\
\hline & \multirow[t]{2}{*}{$3 \mathrm{bps}$} & 8.28 & 8.30 & 7.50 & 7.59 & 7.47 & 7.70 & 8.89 & 9.26 & 7.94 & 8.09 & 10.7 & 10.7 \\
\hline & & (3.83) & (3.77) & (4.01) & (3.96) & (3.23) & $(3.42)$ & $(3.75)$ & (3.93) & $(4.35)$ & $(5.32)$ & $(5.01)$ & (5.08) \\
\hline & \multirow[t]{2}{*}{$3.5 \mathrm{bps}$} & 7.82 & 7.77 & 7.23 & 7.15 & 6.63 & 6.92 & 8.96 & 9.15 & 10.1 & 9.98 & 10.2 & 10.2 \\
\hline & & (3.07) & (2.99) & $(2.95)$ & $(2.86)$ & (3.12) & (3.22) & $(4.65)$ & $(4.55)$ & (3.83) & (3.79) & $(4.92)$ & (5.07) \\
\hline & \multirow[t]{2}{*}{$4 \mathrm{bps}$} & 7.42 & 7.45 & 6.59 & 6.63 & 6.24 & 6.45 & 7.19 & 7.36 & 8.13 & 8.20 & 7.81 & 7.90 \\
\hline & & (2.69) & $(2.69)$ & $(2.53)$ & $(2.59)$ & $(2.37)$ & $(2.42)$ & $(2.15)$ & $(2.20)$ & $(4.06)$ & $(4.12)$ & $(3.87)$ & $(3.92)$ \\
\hline \multirow[t]{16}{*}{ VEL } & \multirow[t]{2}{*}{ Slow } & 73.1 & 47.7 & 71.0 & 56.8 & 75.7 & 62.9 & 98.7 & 56.9 & 82.2 & 71.6 & 121.8 & 64.5 \\
\hline & & (30.4) & $(21.7)$ & $(36.0)$ & $(43.3)$ & (31.8) & (33.3) & $(47.0)$ & $(24.2)$ & (39.5) & $(27.7)$ & (78.6) & (43.7) \\
\hline & \multirow[t]{2}{*}{$\mathrm{Hab}$} & 75.1 & 72.2 & 74.5 & 61.5 & 82.3 & 81.2 & 96.7 & 68.5 & 85.2 & 81.8 & 122.6 & 87.2 \\
\hline & & (30.5) & (39.2) & (33.3) & (26.5) & $(29.2)$ & (35.8) & (35.4) & $(17.0)$ & (45.3) & (37.5) & (73.3) & $(49.2)$ \\
\hline & Fast & 88.8 & 90.0 & 98.3 & 97.6 & 83.0 & 85.8 & 78.4 & 83.9 & 93.3 & 96.2 & 126.0 & 126.1 \\
\hline & & (39.5) & $(43.2)$ & (51.7) & $(47.4)$ & (28.1) & (31.1) & $(27.2)$ & $(21.2)$ & (49.8) & (53.3) & (60.9) & (57.5) \\
\hline & $2 \mathrm{bps}$ & 69.0 & 64.7 & 98.3 & 82.3 & 74.4 & 62.5 & 84.8 & 58.1 & 88.6 & 77.4 & 118.7 & 85.4 \\
\hline & & (30.7) & (31.9) & (68.9) & (77.7) & $(28.7)$ & $(22.7)$ & $(32.8)$ & $(21.3)$ & (44.6) & (39.0) & $(75.4)$ & (57.5) \\
\hline & $2.5 \mathrm{bps}$ & 73.9 & 76.0 & 88.8 & 88.8 & 68.1 & 69.3 & 90.7 & 77.3 & 77.3 & 79.3 & 107.7 & 98.3 \\
\hline & & (34.0) & (39.4) & (54.3) & $(47.3)$ & (23.5) & $(26.3)$ & (42.1) & (33.3) & (32.4) & (32.5) & (62.3) & $(60.2)$ \\
\hline & $3 \mathrm{bps}$ & 80.8 & 82.7 & 82.6 & 86.3 & 74.9 & 76.6 & 94.1 & 90.7 & 76.3 & 81.1 & 111.9 & 112.8 \\
\hline & & (41.5) & $(41.5)$ & (49.2) & $(48.5)$ & (30.5) & $(33.5)$ & $(42.0)$ & $(40.0)$ & (36.9) & $(43.3)$ & $(58.6)$ & (56.7) \\
\hline & $3.5 \mathrm{bps}$ & 87.7 & 88.7 & 84.9 & 85.9 & 72.4 & 76.3 & 108.7 & 106.3 & 107.7 & 109.0 & 123.0 & 124.6 \\
\hline & & (39.5) & $(38.8)$ & $(35.4)$ & $34.2)$ & (33.0) & (34.3) & $(70.0)$ & $(67.0)$ & (38.8) & $(41.8)$ & $(66.1)$ & $(66.7)$ \\
\hline & $4 \mathrm{bps}$ & 98.2 & 99.2 & 92.0 & 93.5 & 78.4 & 80.9 & 92.2 & 92.6 & 102.8 & 104.0 & 106.8 & 108.4 \\
\hline & & (41.2) & $(41.3)$ & $(44.0)$ & $(44.3)$ & $(28.0)$ & $(28.9)$ & (23.9) & $(23.7)$ & (52.3) & $(52.7)$ & (50.6) & (50.8) \\
\hline CSTI & Slow & 9.32 & $4,17)$ & 13.9 & .35) & 13.9 & $2.4)$ & 8.65 & $3.23)$ & 11.6 & $5.92)$ & 9.01 & .99) \\
\hline & $\mathrm{Hab}$ & 10.8 & $4.81)$ & 8.64 & $.62)$ & 9.29 & $.98)$ & 7.72 & $3.35)$ & 12.9 & 12.9) & 10.5 & .73) \\
\hline & Fast & 5.50 & $1.94)$ & 6.66 & .46) & 6.82 & .59) & 5.37 & $2.90)$ & 6.37 & $3.33)$ & 5.00 & .37) \\
\hline & $2 \mathrm{bps}$ & 8.82 & $2.36)$ & 12.1 & $.32)$ & 11.1 & $3.54)$ & 6.81 & $2.14)$ & 10.2 & $5.98)$ & 8.46 & .24) \\
\hline & $2.5 \mathrm{bps}$ & 5.88 & $2.15)$ & 6.50 & $.29)$ & 10.0 & $.22)$ & 5.35 & 1.09) & 9.53 & $5.96)$ & 6.10 & .46) \\
\hline & $3 \mathrm{bps}$ & 6.24 & $2.46)$ & 5.95 & L.89) & 8.24 & $.53)$ & 4.70 & $2.08)$ & 10.7 & $9.81)$ & 6.24 & .69) \\
\hline & $3.5 \mathrm{bps}$ & 4.34 & $1.55)$ & 5.74 & .63) & 6.24 & $.98)$ & 4.98 & 1.56) & 6.06 & .69) & 3.84 & $.48)$ \\
\hline & $4 \mathrm{bps}$ & 5.24 & $0.65)$ & 7.07 & t.28) & 6.09 & $.86)$ & 4.71 & $2.80)$ & 6.90 & $5.15)$ & 5.04 & .77) \\
\hline
\end{tabular}

\section{$2 \quad$ Kinematic data}

3 The means of the kinematic variables are displayed in figure 1. Statistical analyses of

4 the kinematic variables duration, peak velocity, amplitude, and cSTI were calculated

5 separately for pacing condition (self-paced and metronome paced) and task (/pa/, /sa/ 
1 and /ta/). The sections below summarise the results for each kinematic variable in 2 turn. 

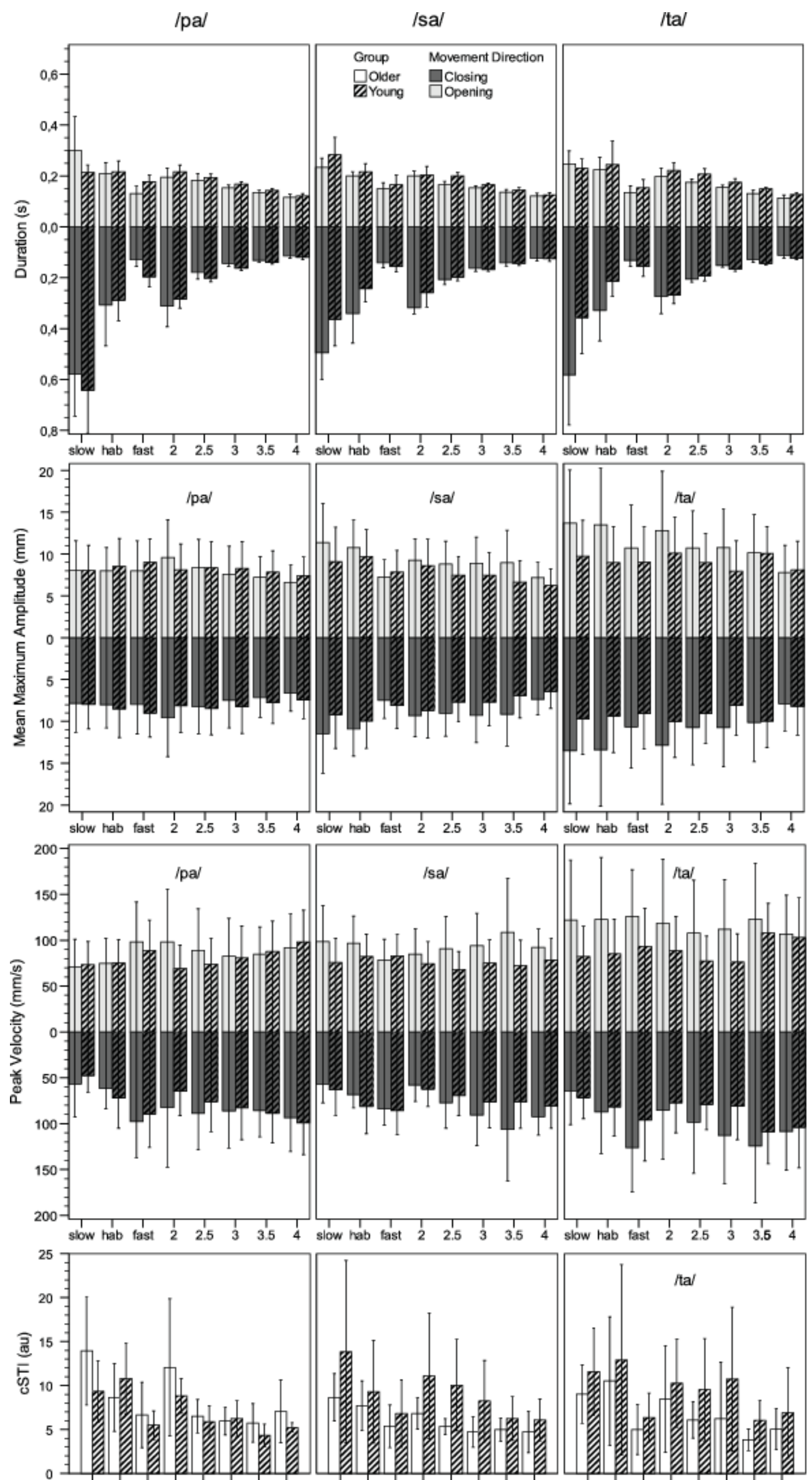
Figure 1. Mean duration, maximum amplitude, peak velocity and csti with 95\% confidence intervals of articulator opening and closing movements for the young and older groups in both pacing conditions. Results are shown separately for speech task.

\section{Duration}

For all syllable repetition tasks and both pacing conditions, the main effect of group on duration of articulatory movements was non-significant. The main effects of rate were all significant; metronome condition $/ \mathrm{pa} /[\mathrm{F}(4,135.82)=122.2, \mathrm{p}<.001], / \mathrm{sa} /$ $[\mathrm{F}(4,41.55)=185.9, \mathrm{p}<.001], / \mathrm{ta} /[\mathrm{F}(4,41.16)=154.0, \mathrm{p}<.001]$, and self-paced condition $/ \mathrm{pa} /[\mathrm{F}(2,27.33)=52.45, \mathrm{p}<.001], / \mathrm{sa} /[\mathrm{F}(2,20.25)=68.30, \mathrm{p}<.001], / \mathrm{ta} /$ $[F(2,24.13)=43.25, \mathrm{p}<.001]$. The effects of direction were also all significant; metronome condition $/ \mathrm{pa} /[\mathrm{F}(1,25.56)=15.76, \mathrm{p}=.001], / \mathrm{sa} /[\mathrm{F}(1,32.56)=57.59, \mathrm{p}<$ $.001]$, and $/ \mathrm{ta} /[\mathrm{F}(1,32.89)=11.39, \mathrm{p}=.002]$, and self-paced condition $/ \mathrm{pa} /$ $[\mathrm{F}(1,41.26)=48.87, \mathrm{p}<.001], / \mathrm{sa} /[\mathrm{F}(1,25.38)=38.25, \mathrm{p}<0.001], / \mathrm{ta} /[\mathrm{F}(1,30.19)=$ 24.04, $\mathrm{p}<.001]$. Across groups, durations were effectively reduced with increasing syllable repetition rate, and closing durations were longer than opening durations. A significant group by rate effect was present in the self-paced condition of /ta/ $[F(2,24.13)=4.74, p=.018$, but no clear pattern was present. Significant interaction effects of group by direction were present for /sa/ and /ta/ in the metronome condition: $[\mathrm{F}(1,32.56)=15.23, \mathrm{p}<.001]$ and $[\mathrm{F}(1,32.89)=5.36, \mathrm{p}=.027]$, and the self-paced condition: $[F(1,25.38)=13.75, p=.001]$ and $[F(1,30.19)=9.57, p=.004]$, showing that the overall difference of opening movements being longer than closing movements, were larger in older compared to younger adults. There were significant interaction effects of rate by direction in the metronome conditions in all tasks: /pa/ $[\mathrm{F}(4,40.89)=6.31, \mathrm{p}<.001], / \mathrm{sa} /[\mathrm{F}(4,49.70)=12.06, \mathrm{p}<.001], / \mathrm{ta} /[\mathrm{F}(4,45.98)=$ 
$14.74, \mathrm{p}=.003]$ and in all self-paced conditions: /pa/ $[\mathrm{F} 2,30.20)=23.36, \mathrm{p}<.001], / \mathrm{sa} /$

$2[\mathrm{~F}(2,24.34)=20.92, \mathrm{p}<.001], / \mathrm{ta} /[\mathrm{F}(2,28.10)=13.30, \mathrm{p}<.001]$, indicating that the

3 difference in duration between closing and opening movements decreased with

4 increasing syllable repetition rate. Significant three-way interaction effects of group

5 by rate by direction were present in the metronome condition in $/ \mathrm{sa} /[\mathrm{F}(4,49.70)=$

$64.57, \mathrm{p}=.003]$ and $/ \mathrm{ta} /[\mathrm{F}(4,45.98)=2.86, \mathrm{p}=.034]$ and the self-paced condition of

$7 \quad / \mathrm{sa} /[\mathrm{F}(2,24.34)=5.75, \mathrm{p}=.009]$ and $/ \mathrm{ta} /[\mathrm{F}(2,28.10)=5.06, \mathrm{p}=.013]$, indicating

8 that, especially at slower syllable repetition rates, the older adults showed a larger

9 difference in duration between closing and opening movements, compared to younger 10 adults.

$\underline{\text { Movement Amplitude }}$

13 The analysis showed no significant main effects of group. Significant main effects of 14 rate were found in the metronome condition of $/ \mathrm{sa} /[\mathrm{F}(4,16.01)=3.14, \mathrm{p}=.014]$, and $15 / \mathrm{ta} /[\mathrm{F}(4,15.65)=7.38, \mathrm{p}=.002]$, as well as in the self-paced condition of $/ \mathrm{sa} /$ $16[\mathrm{~F}(2,16.00)=8.19, \mathrm{p}=.004]$. Significant effects of direction were also found in the 17 metronome condition of $/ \mathrm{sa} /[\mathrm{F}(1,16.00)=57.90, \mathrm{p}<.001]$, and $/ \mathrm{ta} /[\mathrm{F}(1,16.08)=$ $186.69, \mathrm{p}=.020]$, and in the self-paced condition of $/ \mathrm{sa} /[\mathrm{F}(1,16.00)=25.91, \mathrm{p}<.001]$.

19 In these cases, an increase in rate was associated with a decrease in movement range, and the mean amplitude of closing movements was larger compared to opening

21 movements. The group by rate interaction effect was significant in the metronome condition of $/ \mathrm{ta} /[\mathrm{F}(4,15.65)=5.64, \mathrm{p}=.005]$, and the rate by direction interaction

23 was significant in the metronome condition of $/ \mathrm{sa} /[\mathrm{F}(4,16.00)=12.14, \mathrm{p}<.001]$, and 24 the self-paced conditions of $/ \mathrm{pa} / \mathrm{F}(2,16.00)=4.25, \mathrm{p}=033]$ and $/ \mathrm{ta} /[\mathrm{F}(2,15,59)=$ $254.41, \mathrm{p}=.030]$, but inspection of the data did not reveal a clear pattern. An interaction 
1 effect of group by direction was present in the self-paced condition of /ta/: [F(1,14.80)

$2=9.71, \mathrm{p}=.007]$, showing that the younger adults displayed slightly larger amplitudes

3 of closing movements compared to opening movements, while the older adults

4 displayed a slight reverse effect.

$\underline{\text { Peak Velocity }}$

7 The results of the statistical analyses of peak velocity of articulatory movements

8 revealed no significant main effect of group. The main effect of rate was significant in

9 the metronome condition of $/ \mathrm{pa} /:[\mathrm{F}(4,16.00)=7.43, \mathrm{p}=.001], / \mathrm{sa}, /:[\mathrm{F}(4,16.00)=$

$104.32, \mathrm{p}=.015]$, and $/ \mathrm{ta} /[\mathrm{F}(4,15.76)=14.89, \mathrm{p}<.001]$, and the self-paced condition of

$11 \mathrm{ha} /: \mathrm{F}(2,16.00)=11.91, \mathrm{p}=.001], / \mathrm{sa} /:[\mathrm{F}(2,16.00)=6.28, \mathrm{p}=.010]$, and $/ \mathrm{ta} /:$

$12[\mathrm{~F}(2,15.78)=8.12, \mathrm{p}=.004]$, showing that an increase in syllable repetition rate was

13 associated with an increase in maximum velocity. A significant main effect of

14 direction was present in the metronome condition of $/ \mathrm{sa} /:[\mathrm{F} 1,16.00)=14.22, \mathrm{p}=$

$15.002]$ and $/ \mathrm{ta} /:[\mathrm{F}(1,15,47)=5.58, \mathrm{p}=.032]$, and in the self-paced condition of $/ \mathrm{pa} /$

$16[\mathrm{~F}(1,16.00)=17.33, \mathrm{p}=.001], / \mathrm{sa} / \mathrm{F}(1,16.00)=20.54, \mathrm{p}<.001]$, and $/ \mathrm{ta} /[\mathrm{F}(1,16.08)$

$17=13.44, \mathrm{p}=.002]$, indicating that the maximum velocity was higher in opening

18 movements, compared to closing movements. This difference decreased with an

19 increasing syllable repetition rate, indicated by significant rate by direction effects in

20 the metronome condition of $/ \mathrm{sa} /[\mathrm{F}(4,16.00)=9.60, \mathrm{p}<.001]$ and $/ \mathrm{ta} /[\mathrm{F}(4,15.61)=$

$216.50, \mathrm{p}=.003$, and in the self-paced conditions of $/ \mathrm{pa} /[\mathrm{F}(2,16.00)=15.71, \mathrm{p}<.001$,

$22 / \mathrm{sa} /[\mathrm{F}(2,16.00)=12.26, \mathrm{p}=.001]$, and $/ \mathrm{ta} /[\mathrm{F}(2,15.58)=9.34, \mathrm{p}=.002]$. A

23 significant interaction effect of group by rate in the metronome condition of $/ \mathrm{ta} /$

$24[\mathrm{~F}(4,15.65)=5.26, \mathrm{p}=.007]$ did not reveal a clear pattern. Significant interaction

25 effects of group by direction were present for $/ \mathrm{sa} /$ and $/ \mathrm{ta} /$ in the metronome 
1 condition: $[\mathrm{F}(1,16.00)=11.18, \mathrm{p}=.004]$ and $[\mathrm{F}(1,15.47)=4.56, \mathrm{p}=.049]$, and the

2 self-paced condition: $[\mathrm{F}(1,16.00)=10.27, \mathrm{p}=.006]$ and $[\mathrm{F}(1,16.08)=8.38, \mathrm{p}=.011]$,

3 showing that the overall differences of maximum velocities between opening and

4 closing movements were larger in older adults compared to younger adults.

5 Furthermore, a significant three-way interaction effect of group by rate by direction

6 was observable in the metronome condition of $/ \mathrm{sa} /[\mathrm{F}(4,16.00)=3.33, \mathrm{p}=.036]$, and

7 the self-paced condition of $/ \mathrm{sa} /[\mathrm{F}(2,16.00)=5.10, \mathrm{p}=.019]$, and $/ \mathrm{ta} /[\mathrm{F}(2,15.58)=$

$83.71, \mathrm{p}=.048]$, indicating that both the direction and the rate effects were only

9 present in the older adults, whereas no such effects were present in the younger

10 adults. These findings show that, especially at slower syllable repetition rates, the

11 older adults showed a larger difference in peak velocity between closing and opening 12 movements, compared to younger adults.

\section{Cyclic Spatiotemporal Index}

15 Statistical analysis of the cSTI did not reveal differences between younger and older

16 adults as evidenced by a non-significant group effect. A significant effect of rate was

17 present in all tasks in the metronome condition: $/ \mathrm{pa} /:[\mathrm{F}(4,16.00)=9.11, \mathrm{p}<.001]$,

$18 \mathrm{sa} /: \mathrm{F}(4,16.00)=4.86, \mathrm{p}=.009], / \mathrm{ta} /:[\mathrm{F}(4,16)=4.20, \mathrm{p}=.016]$, and all tasks in the

19 self-paced condition: $/ \mathrm{pa} /:[\mathrm{F}(2,16.00)=19.23, \mathrm{p}<.001], / \mathrm{sa} /:[\mathrm{F}(2,16.00)=4.17, \mathrm{p}=$

$20.035]$, and $/ \mathrm{ta} /:[\mathrm{F}(2,16.00)=12.35, \mathrm{p}<.001]$, indicating that $\mathrm{cSTI}$ decreased with

21 increasing syllable repetition rate. A significant interaction effect of group by rate was

22 present in the self-paced condition of $/ \mathrm{pa} /[\mathrm{F}(2,16.00)=13.33, \mathrm{p}<.001]$ and the

23 metronome paced condition of $/ \mathrm{sa} /[\mathrm{F}(4,16.00)=3.12, \mathrm{p}=.045]$, but further group

24 comparisons revealed no clear pattern. 


\section{Discussion}

3 In this study, the influence of syllable repetition rate on articulation movements of

4 younger and older adults was investigated with the aim of assessing the effects of

5 aging on the kinematic characteristics and stability of articulation movements

6 produced at different syllable repetition rates. The results showed that older adults

7 were able to repeat syllables as fast as younger adults (or even faster) when stimulated

8 (by instruction or external metronome cues) to do so. These findings suggest that

9 possible physiological changes to speech systems associated with aging are minimally

10 disruptive (see also [7]). Alternatively, older adults have acquired effective

11 compensatory behaviours for possible physiological changes, at least in the case of

12 the relatively simple syllable repetition tasks used in this study.

The kinematic results confirm a close relation between syllable repetition rate

14 and movement duration as found in earlier studies $[6,8,9,11]$. Since both groups

15 showed overall longer durations in closing movements compared to opening

16 movements, and closing durations were proportionally more reduced with increasing

17 rate, it can be concluded that the increase in rate was primarily achieved by actively

18 reducing the closing duration. When producing the alveolar constrictions associated

19 with $/ \mathrm{sa} /$ and $/ \mathrm{ta} /$ at slower rates, the older adults made a larger differentiation between

20 closing and opening movements, compared to the younger adults, suggesting that for

21 the tongue tip, older adults control articulation differently at slow rates than younger

22 adults. In contrast, Goozee et al. [11] reported longer durations of opening movements

23 compared to closing movements. This difference could be due to the use of different

24 stimuli and the methods through which changes in syllable repetition rate were

25 induced. 
With respect to the amplitude of articulatory movements, the younger and

2 older adults reduced tongue movement amplitude with increasing speech rate in both

3 pacing conditions for $/ \mathrm{sa} /$ and in the self-paced condition of $/ \mathrm{ta} /$. During these speech

4 tasks closing movements were larger than opening movements. This asymmetry

5 suggests that speakers increased or decreased their speech rate during trial repetitions

6 [17]. However, since tongue tip movements were not corrected for jaw movements, it

7 cannot be ruled out that jaw movements contributed to the results found, and should

8 be confirmed in future research.

An increase in syllable repetition rate is usually associated with an increase in peak velocity [17]. The current study corroborates these findings. In most tasks, both

11 age groups showed lower velocities during closing movements compared to opening

12 movements. During the production of the alveolar constrictions of /sa/ in both pacing 13 conditions and for $/ \mathrm{ta} /$ in the self-paced condition, the group of older adults showed a 14 significantly larger difference in peak velocity between closing and opening 15 movements, and this effect was most notably present in the slower rates, mimicking 16 the effects found for movement duration.

How can the current kinematic findings be explained in the absence of speed 18 or stability limitations? In experimental tasks where capacities have to be distributed 19 across articulation rate and stability, speakers may focus on one or the other, 20 depending on their skills and task priorities [11]. Contrary to our hypothesis, the 21 results of the present study showed that older adults realized equal and faster syllable 22 repetition rates compared to the young group, without changes in articulation stability. 23 With increasing rates, movements made by older adults became more similar, in that 24 the differences in duration and peak velocity between closing and opening movements decreased, mimicking the pattern typically displayed by the younger adults. Greater 
1 similarity between opening and closing movement sequences often reflects a more open loop or ballistic type of motor control $[8,15]$. Vice versa, the current findings

3 that the older adults -but not the younger adults- increased the duration (and decreased

4 peak velocity) of closing movements more than opening movements at slower rates

5 can be interpreted as the result of a less ballistic mode of control. It has been

6 demonstrated that slowing down articulation facilitates closed loop (feedback based)

7 control, enabling the online detection of movement errors and subsequent computation and integration of corrections [22]. At faster rates, closed loop control is

9 not possible, as corrective movements are ineffective for on-going speech sound

10 sequences [23]. Based on the present results, we hypothesize that older adults may

11 utilize a control strategy facilitating feedback control of tongue movements when 12 speaking at a relatively slower rate. This might be linked to age-related changes in 13 cognitive processing during speech and/or structural changes in the speech production 14 system. For example, several studies suggested that aging is related to a decrease in 15 general oral sensory function [24,25]. Specifically, Weismer and Liss [1] suggested 16 an age-related decrease in proprioception for active tongue movements based on their 17 findings that older adults were less able to judge the required durations and velocities 18 of lifting the tongue in executing speech tasks. If indeed with increasing age the 19 quality of somatosensory information of (especially) tongue movements decreases, 20 this could force older adults to adapt control strategies, in particular with a stronger 21 reliance on closed loop control. We speculate that for older speakers, the stronger 22 slowing down of closing movements may compensate for a reduced quality of 23 sensory information, enabling the use of closed loop control and allowing a more 24 extensive processing. If this were true, kinematic differences with respect to duration 25 and peak velocity of closing movements between older and younger speakers would 
1 disappear when speakers are forced to use a more open loop control through a

2 paradigm that masks auditory feedback (through noise) and (part of) proprioceptive

3 feedback (through tendon vibration), possibly at the cost of a reduced articulatory

4 stability for older speakers. These apparent age-related differences in speech motor

5 control as a function of self-paced and externally timed repetition rates are in line

6 with earlier studies using syllable repetition experiments to study speech performance

7 in clinical populations [e.g. 26], and can provide insight in limitations in speech

8 production due to age and its relationship to potentially affected neural systems.

9 Speech motor control reserve capacities in healthy aging speakers may mask speech

10 problems, and only when additional disease processes affecting the oromotor control

11 system appear (in particular dysarthria), a divergent speech output becomes more 12 salient [26,27].

It should be noted that the interpretation of the data leading to our hypothesis

14 is constrained in various aspects. To be able to fully investigate our predictions, future

15 directions should be geared towards investigating movements of additional

16 articulators, including the jaw and the tongue dorsum, as well as their relative role

17 during articulation as a function of age. More natural speech stimuli could be used,

18 and in addition to measuring articulatory stability by means of the cSTI or other

19 speech variability measures, perceptual measurements should be included to further

20 assess the role of speech intelligibility in age-related changes in speech motor control.

\section{Acknowledgements}

23 The authors gratefully thank the participants for their time and effort, Aukje Lingsma

24 and Sarah Klein for their help in data collection, and Hugo Quené for his statistical 
1 advice. This study was partially supported and funded by the Utrecht Institute of

2 Linguistics (UiL OTS), Utrecht University, The Netherlands.

\section{Declaration of interest}

5 The authors report no conflicts of interest. The authors alone are responsible for the

6 content and writing of the paper.

\section{References}

9 1. Weismer G, Liss JM: Speech motor control and aging; in Ripich DN (ed):

10 Handbook of Geriatric Communication Disorders. Austin, Pro-Ed, 1991, 205-225.

11 2. Cecilio FA, Regalo SCH, Palinkas M, Issa JPM, Siessere S, Hallak JEC,

12 Machado-de-Sousa JP, Semprini M: Ageing and surface EMG activity patterns of 13 masticatory muscles. J Oral Rehabil 2010;37:248-255.

14 3. Butler SG, Stuart A, Leng X, Wilhelm E, Rees C, Williamson J, Kritchevsky 15 SB: The Relationship of Aspiration Status With Tongue and handgrip strength in 16 healthy older adults. J Gerontol A Biol Sci Med Sci 2011;66A:452-458.

17 4. Crow HC, Ship JA: Tongue strength and endurance in different aged 18 individuals. J Gerontol A Biol Sci Med Sci 1996;51A:247-250.

19 5. Duchin SW, Mysak ED: Disfluency and rate characteristics of young adult, 20 middle aged, and older males. J Commun Disord 1987;20:245-257.

21 6. Smith B, Wasowicz J, Preston J: Temporal characteristics of the speech of 22 normal elderly adults. J Speech Hear Res 1987;30:522-529.

23 7. Bennett JW, van Lieshout PH, Steele CM: Tongue control for speech and 24 swallowing in healthy younger and older subjects. Int $\mathrm{J}$ Orofacial Myology 2007;33:5-18. 
18 . Ostry DJ, Munhall KG: Control of rate and duration of speech movements. J

2 Acoust Soc Am 1985;77:640-648.

3 9. Adams SG, Weismer G, Kent RD: Speaking rate and speech movement

4 velocity profiles. J Speech Hear Res 1993;36:41-54.

5 10. Goozee JV, Lapointe LL, Murdoch BE: Effects of speaking rate on EMA-

6 derived lingual kinematics: a preliminary investigation. Clin Linguist Phonet $7 \quad 2003 ; 17: 375-381$.

8 11. Goozee JV, Stephenson DK, Murdoch BE, Darnell RE, Lapointe LL: Lingual

9 kinematic strategies used to increase speech rate: comparison between younger and 10 older adults. Clin Linguist Phonet 2005;19:319-334.

11 12. Amerman JD, Parnell MM: Speech timing strategies in elderly adults. J Phon $12 \quad 1992 ; 20: 65-76$.

13 13. Terband H, Maassen B, van Lieshout P, Nijland L: Stability and composition 14 of functional synergies for speech movements in children with developmental speech 15 disorders. J Commun Disord 2011;44:59-74

16 14. Davidow JH, Bothe AK, Richardson JD, Andreatta RD: Systematic studies of 17 modified vocalization: effects of speech rate and instatement style during metronome 18 stimulation. J Speech Lang Hear Res 2010;53:1579-1594.

19 15. Van Lieshout PHHM, Bose A, Square PA, Steele CM: Speech motor control 20 in fluent and dysfluent speech production of an individual with apraxia of speech and 21 Broca's aphasia. Clin Linguist Phonet 2007;21:159-188.

22 16. Westbury JR, Lindstrom MJ, McClean MD: Tongues and lips without jaws: a 23 comparison of methods for decoupling speech movements. J Speech Lang Hear Res $24 \quad 2002 ; 45: 651-662$. 
1 17. Hertrich I, Ackermann H: Lip-jaw and tongue-jaw coordination during rate-

2 controlled syllable repetitions. J Acoust Soc Am 2000;107:2236-2247.

3 18. Henriques RN, Lieshout Pv: A comparison of methods for decoupling tongue

4 and lower lip from jaw movements in 3d articulography. J Speech Lang Hear Res $5 \quad 2013 ; 56: 1503-1516$.

6 19. Smith A, Goffman L, Zelaznik HN, Ying G, McGillem C: Spatiotemporal

7 stability and patterning of speech movement sequences. Exp Brain Res 1995;104:4938501.

9 20. Quené H, van den Bergh H: Examples of mixed-effects modeling with crossed 10 random effects and with binomial data. J Mem Lang 2008;59:413-425.

11 21. Rothman KJ: No adjustments are needed for multiple comparisons. 12 Epidemiology 1990:43-46.

13 22. Terband H, Maassen B: Speech motor development in childhood apraxia of 14 speech: generating testable hypotheses by neurocomputational modeling. Folia 15 Phoniatr Logop 2010;62:134-142.

16 23. Guenther FH: Cortical interactions underlying the production of speech 17 sounds. J Commun Disord 2006;39:350-365.

18 24. Ikebe K, Amemiya M, Morii K, Matsuda K, Furuya-Yoshinaka M, Nokubi T: 19 Comparison of oral stereognosis in relation to age and the use of complete dentures. $\mathrm{J}$ 20 Oral Rehabil 2007;34:345-350.

21 25. Kawagishi S, Kou F, Yoshino K, Tanaka T, Masumi S: Decrease in 22 stereognostic ability of the tongue with age. J Oral Rehabil 2009;36:872-879.

23 26. Ackermann H, Hertrich I, Hehr T: Oral diadochokinesis in neurological 24 dysarthrias. Folia Phoniatr Logop 1995;47:15. 
1 27. Rong P, Loucks T, Kim H, Hasegawa-Johnson M: Relationship between 2 kinematics, $\mathrm{f} 2$ slope and speech intelligibility in dysarthria due to cerebral palsy. Clin 3 Linguist Phonet 2012;26:806-822.

4

5 